\title{
Qualitative developmental research among low income African American adults to inform a social marketing campaign for walking
}

Dawn K Wilson 1*, Sara M St.George ${ }^{1}$, Nevelyn N Trumpeter ${ }^{1}$, Sandra M Coulon', Sarah F Griffin², Abe Wandersman ${ }^{1}$, Melinda Forthofer ${ }^{3}$, Barney Gadson ${ }^{4}$ and Porschia V Brown ${ }^{1}$

\begin{abstract}
Background: This study describes the development of a social marketing campaign for increasing walking in a low income, high crime community as part of the Positive Action for Today's Health (PATH) trial.

Methods: Focus groups were conducted with 52 African American adults (ages 18 to 65 yrs), from two underserved communities to develop themes for a social marketing campaign to promote walking. Participants responded to questions concerning social marketing principles related to product, price, place, promotion, and positioning for increasing neighbourhood walking.

Results: Focus group data informed the development of the campaign objectives that were derived from the " 5 Ps" to promote physical and mental health, social connectedness, safety, and confidence in walking regularly. Focus group themes indicated that physical and mental health benefits of walking were important motivators. Walking for social reasons was also important for overcoming barriers to walking. Police support from trusted officers while walking was also essential to promoting safety for walking. Print materials were developed by the steering committee, with a 12-month calendar and door hangers delivered to residents' homes to invite them to walk. Pride Stride walks empowered community walkers to serve as peer leaders for special walking events to engage new walkers.
\end{abstract}

Conclusions: Essential elements for developing culturally tailored social marketing interventions for promoting walking in underserved communities are outlined for future researchers.

Keywords: Social marketing, African American, Walking, Physical activity, Health promotion

\section{Background}

National studies have shown that physical inactivity is more prevalent among African American adults than non-minority adults [1]. These findings have led to an increasing national priority for increasing knowledge about the determinants and mediating factors of physical inactivity, especially among minority communities [2-5]. Previous research has demonstrated that underserved communities (low-income, predominately minority) have a number of environmental barriers that limit their engagement in walking, including concerns about safety,

\footnotetext{
*Correspondence: wilsondk@mailbox.sc.edu

'Department of Psychology, University of South Carolina, Columbia, SC 29208, USA

Full list of author information is available at the end of the article
}

stray dogs, lack of group participation, and lack of available facilities and opportunities for physical activity (PA) [6-16]. This study describes the formative development of a social marketing campaign that targeted improving perceptions of safety, access, psychosocial and social environmental barriers related to walking among residents living in low-income, high crime communities as part of the Positive Action for Today's Health (PATH) trial [17].

Social marketing is an approach which targets specific audiences with marketing strategies to improve personal health and quality of life, such as increasing walking [18]. In general, there are five major components of developing social marketing strategies, which include the "5 Ps:" (1) product, (2) price, (3) place, (4) promotion, and (5) positioning. Product refers to the target behavior, 
such as increasing walking. Price refers to the social, economic, and psychological costs involved in adopting the behavior such as walking. Place refers to the setting, community context, or distribution channels for the product (walking behavior). Promotion includes all actions designed to make the audience aware of the ideas, behaviors, and benefits of walking that may include interpersonal communication, media messages, grassroots approaches, special events and incentives. Positioning (also known as exchange), refers to the framing of the product (walking behavior) so that the perceived benefits are maximized and the perceived costs are minimized. Additional principles of social marketing include an understanding of (1) audience segmentation, including the creation of tailored messages, incentives, and opportunities that appeal to community subgroups, (2) channel analysis, which entails identification of communication pathways most likely to reach identified community subgroups, (3) identifying target markets through consumer research and (4) process tracking for documenting adherence to planned strategies [18-22].

Social marketing is a widely accepted approach in the field of health promotion [23,24]. Research on social marketing and the promotion of walking and physical activity has been reviewed by Alcalay and Bell [20]. Previous investigators have typically failed to have measurable objective outcomes, apply behavioral theory, use audience segmentation beyond basic demographics, conduct consumer research about the audiences of interest, and pre-test concepts and health communication messages. Whereas other social marketing approaches for increasing PA have placed greater emphasis on the individual-level [20], the present social marketing campaign also highlights the social and community-wide benefits of walking. This study specifically expands on past qualitative work by using principles based on Social Ecological Theory $[25,26]$ and Social Cognitive Theory $[27,28]$ to explore social environmental barriers and facilitators for improving motivation and self-confidence for walking and exercising regularly. Compared to studies reviewed by Alcalay and Bell [20], those reviewed by Yancey and colleagues [29], which targeted ethnic minority communities, were more heavily focused on community norms and activities. The current social marketing campaign specifically targeted community norms by focusing on family and community connectedness in the overall approach. In addition, the PATH trial addressed previous limitations by using a formative evaluation process that incorporated behavioral principles, audience segmentation, and consumer audience input to create a social marketing strategy to promote community walking.

A growing body of evidence suggests it is important to tailor social marketing approaches to increase social environmental supports for walking. Previous research has focused on improving key social environmental factors including community connectedness, collective efficacy, social networks, and social support in developing social marketing approaches [30-40]. Specifically, previous investigators have examined these factors to more fully understand the relation between social factors and walking and PA outcomes [30-38,40]. In a review of interventions for promoting walking, it has demonstrated that social support was strongly and positively associated with increased levels of walking and PA $[30,32,35,37,39,41]$. In a study by McNeil et al. [36] both social and physical environmental supports had indirect effects on PA, and social support influenced PA through increasing motivation. Fisher et al. [33] found that community connectedness was significantly associated with increased levels of neighborhood walking and PA and positive social interactions for PA in adults. The social marketing approach in this study targeted intrapersonal level variables such as beliefs, motivation, and selfefficacy related to walking as well as social environmental factors such as perceptions of neighborhood safety, social support, and community connectedness.

The overall goal of the PATH trial was to develop and evaluate the efficacy and cost-effectiveness of a walking intervention for increasing PA in low-income, high crime communities [17]. Three communities were randomized to receive one of three programs: a police- patrolled walking program plus social marketing campaign (full intervention), a police-patrolled walking only program (walking only intervention), or no walking, general health education program (comparison program). This article describes the formative work to develop a social marketing intervention that targeted determinants of walking, neighborhood safety and access for walking, as well as psychological and social factors related to increasing walking in the full intervention community in South Carolina (SC) that specifically targeted older African American women and men.

\section{Methods}

\section{PATH intervention community - focus groups \\ Participants}

Post-randomization of the PATH trial [17], five focus groups were conducted in two underserved communities (including the PATH intervention community) to tailor the social marketing campaign to the specific needs of the community. Participants for the focus groups were recruited through the local neighbourhood association in Sumter, SC and through a local school that was in a neighbourhood that was matched on geographical demographics to Sumter including percent minorities, poverty, and crime rates. Participants $(n=52$; mean age $=64$ years) were primarily African American and 
included equal numbers of men and women (see Table 1). Community partners provided a list of contacts from local neighborhood associations and asked school staff who were older African American adults to participate given that the PATH trial would target a similar population for the walking program. All individuals on the list were contacted by telephone and personally invited to participate. Participants answered questions about walking in their community, including what they would want in a neighborhood walking program and how to overcome obstacles such as crime.

\section{Focus group protocols}

The focus group sessions were conducted by the principal investigator and research staff using a standardized protocol of questions and probes. The protocol of questions and probes were pilot tested on African American staff at the University of South Carolina prior to conducting the focus groups. Participants completed an informed consent prior to participating and then a short demographic survey.

\section{Data coding and analyses}

The coding scheme was composed of "levels" of categorization of the qualitative data. An initial code book was developed based on expected responses and outlined theoretical constructs. After an initial review of the focus group transcripts, the code book was revised

Table 1 Participant demographics

\begin{tabular}{lc}
\hline Demographic characteristics & ( $\mathbf{n} \mathbf{5 2}$ ) \\
\hline Gender & 31.0 \\
$\quad$ Male & 69.0 \\
$\quad$ Female & \\
Race & 96.0 \\
$\quad$ African American & 4.0 \\
$\quad$ Caucasian & \\
Age, years & 2.0 \\
18-24 & 31.0 \\
25-44 & 50.0 \\
45-64 & 12.0 \\
65+ & 5.0 \\
Unknown & \\
Marital Status & 19.0 \\
Single & 60.0 \\
Married & 14.0 \\
Divorced & 4.0 \\
Separated & 0 \\
Widowed & 3.0 \\
Unknown &
\end{tabular}

Note: the values are expressed as percentages. to more appropriately represent the data. As perceptions, ideas, and suggestions were identified, they were classified into categories or "themes," which were ultimately used to summarize the data [42]. Decision rules were developed to guide and facilitate the coding of the data by using hypothetical situations to illustrate how responses were to be coded. Coders were provided a copy of both the code book and decision rules.

After the recorded focus groups were transcribed by an outside agency, the transcript was checked for accuracy against the original recordings. The transcript was coded by independent raters and inter-rater reliability estimates were calculated $(r=.70)$. Individual raters met to discuss each coding disagreement until a consensus was met regarding the final codes. Once the transcript was coded the codes were entered into QSR NVivo for content analysis structures as outlined by Miles and Huberman [43]. Themes were defined as concepts discussed by at least two different participants. Codes were subsequently cross-referenced to each respective participant. Once codes were applied to all transcripts, QSR NVivo was used to extract coded participant responses. Separate analyses were conducted for men and women to assure that themes for both sexes could be integrated into the social marketing campaign.

\section{Results}

\section{Focus groups}

\section{Product/Place themes for walking and PA}

To determine how and where a program should be implemented, it was imperative to understand walking behavior and influences. Both men and women indicated that their neighborhood and local parks were their primary walking locations (see Table 2). Regarding neighborhood walking, one male participant said, "In my neighbourhood, and it's just like I said, a nice circular, I call it a circuit that I can walk, nice hills and everything." Males and females also had similar responses regarding walking partners. Both men and women reported walking with family members, including adults and children.

When asked about desired aspects of a walking trail, participants provided a variety of responses. Males and females both reported wanting trusted police officers. For example, one male shared, "I don't care how well you feel unless you got a police every 10 to 15 minutes. ... There's some crazy people in this world. ..." An open view of surroundings was also desired, "if you're walking you want to see your children." Participants also articulated the importance of trail cleanliness and attractiveness. "You can't, you know, just can't put it any place, you need to have it in a pleasant location, a pleasant site where it will be enjoyable for yourself and the kids." Participants even went as far as thinking about how weather would affect 


\section{Table 2 Summary of results (Product/Place)}

\section{Question \& theme \\ Where participants walk}

Neighborhood

Park

\section{Who participants walk with}

\section{Adult family member}

Child family member

Unspecified family member

Friends

Self

\section{What participants want \\ in a walking trail}

Trusted police officers

Open view

Stations on trail

Cleanliness/Aesthetic

Safety

Weather provisions
Males

Females
"In my neighborhood, and it's just like I said a nice circular, I call it a circuit

"We'd go walking together at Caughman Road Park."

\section{"I walk with my wife."}

"I go walking with my daughter, and my little son."

"I don't care how well you feel and unless you got a police every 10 to 15 minutes. There's some crazy people in this world."

". . if you're walking you want to see your children."

"... because if you have walking trails you have other things where the kids can play basketball or whatever, you know, the family will enjoy it because the adults may enjoy walking, but the kids not gonna walk."

"You can't, you know, just can't put it any place, you need to have it in a pleasant location, a pleasant site where it will be enjoyable for yourself and the kids.

"I like to walk on a path that's safe, but I think you have to take time to look at, to look at the area and people that are gonna be using it because I think if you're uncomfortable on it, be it male or female, you're not gonna go on it."

"When it's summertime, we want to be outside. You know, we want to see the sun, we want to-all that stuff, flowers... when it's cold we want to be inside not on that walking trail. that I can walk, nice hills and everything."

"Attract, attractiveness, you know, as you say, making it attractive where a, a place where people would want to be."

"More people would participate I think if they knew they had protection."

Would there be some provisions for inclement weather? If you want to, you know, if you're a preacher of routine and you walk everyday at 5:00"

"You know those signs where you're at this point and you're, you can get to this point? 
the trail, with one participant asking, "Would there be some provisions for inclement weather?"

Safety was the most salient theme that emerged from data in the product portion of the formative focus groups. For example, "I like to walk on the path [that] can be set up that's safe, but I think you have to take time to look at, to look at the area and people that are gonna be using it because I think if you're uncomfortable on it, be it male or female, you're not gonna go on it," and "More people would participate I think if they knew they had protection."

\section{Product benefits for walking and PA}

Although benefits of exercise and walking are commonly known, it was important to understand the participants' perceptions of these benefits (see Table 3). Participants were first asked to share their opinions on the best things about exercise. Both males and females cited stress relief, and male participants additionally mentioned physical fitness and mental wellness as benefits. In addition to stress relief, female participants commented on increased energy, health, and weight-related benefits.

After discussing the best things about exercise in general, participants were prompted to discuss the best things about walking specifically. Male and female participants both mentioned meditation time as a walking benefit, "When I'm walking ... I can do a lot of thinking and a lot of things will come to me that I, I do a lot of studying. I can think more, it will be more clear to me and I can see a lot of things." Additionally, female participants noted spending time outside, family bonding time, and health benefits as additional benefits of walking. "When I walk I observe the trees, many different animals that I haven't seen in a long time, you know, I'll stop and look at them or, you know, just take in the fresh air, you know, that can be very relaxing."

Participants were asked about environmental factors which make walking convenient and fun. For both males and females, having a location close to home for walking emerged as an environmental factor which would make walking easy for them. One participant said, "I run at the park and it's only like a 30 second drive away from me." Participants also mentioned that having a way to measure their walking distance would make walking more convenient. "They have a track there now that's really nice, you know, be able to walk on and they actually have a scale that kind of measures your distance." With regard to environmental factors which make walking enjoyable, male and female participants both listed aesthetics saying, "the scenery, especially in the spring and in the fall of the year is really beautiful and sometimes it gets your attention." Female participants additionally noted that the presence of other people makes walking fun, "what makes it fun for me is I run into people that I know."

\section{Price of walking and PA}

To understand the costs associated with a community program targeted at increasing walking and PA, participants were asked to identify environmental and nonenvironmental barriers they experience and believe others experience (see Table 4). Participants cited time, lack of motivation and tending to kids/family as nonenvironmental barriers to exercise. Female participants additionally added "work" as a barrier. With regard to walking specifically, female participants noted that a lack of motivation, time, and a walking partner served as barriers to walking.

In an effort to more fully understand environmental barriers, participants were asked about environmental factors which make it difficult to exercise and walk. Previously mentioned as an important factor to be included in a walking trail, safety emerged a major environmental barrier for participants. Lack of access to facilities in the community was also a theme that emerged as an environmental exercise barrier, "If there's no facility for you to exercise, you have to pay." Female participants also listed inadequate lighting and dogs as environmental barriers to both exercise and walking. Specific to walking, female participants noted that uneven terrain interfered with their walking, "the roads are hilly and then they have big rocks that hurt your feet, honestly you're tired before you reach the road, you're tired." Male participants also mentioned traffic. To overcome these barriers, participants suggested increased lighting as a solution, "come on through and put in more lighting in our neighborhood."

With regard to interpersonal influences on walking and exercise behaviour, male and female participants cited neighbors, friends, and family members as some of the most important influences. For example, "My neighbour, gosh, he gets out no matter what the weather's like and he runs and I'm sure the area that, the circle that he takes is probably about a half a mile, three-quarters of a mile and he'll run that thing. ." Female participants also thought they, themselves, as well as the elderly influence their walking and exercise behavior and said the following, "it's knowing that I have to do something, I have to be active for my own survival" and "what motivates me also too is when I see people that are older than me and they are so fit."

\section{Promotion of walking and PA}

To determine how participants would promote a walking trail, participants were asked what they would say and do to get others active (see Table 5). Additionally, they were asked who they would get out walking first and what messages would be best to use to get others out. Both male and female participants shared that walking with others would be a primary strategy for getting 
Table 3 Summary of results (Product Benefits)

\begin{tabular}{lll}
$\begin{array}{l}\text { Question \& } \\
\text { theme }\end{array}$ & Males & Females \\
\hline
\end{tabular}

\section{Best things}

about Exercising

Relieves stress/ "I really enjoy working out because it's a stress release."

tension

Being physically "it gives me a joy to, to be able to exercise my body so that I can stay physically fit."

Mental "it helps you clear your mind to just feel better, especially when you do it in the wellness morning times, you know. You just feel better all day."

Health

Weight

Increased

energy

\section{Best things}

\section{about walking}

Meditation

time

"When I'm walking, I, I get a lot of, I can do a lot of thinking and a lot of things will come to me that I, I do a lot of studying. I can think more, it will be more clear to me and I can see a lot of things and hear a lot of things and I, like that because it, it's nothing there to block me."

Outside time

Family bonding

time

Health benefits

\section{Environmental}

"Convenience"

factors

Close location

A way to

measure walk
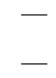

"enjoying walking through the neighborhood"

"you look forward to the possibility of going down a size and so that, you know, that gives you that incentive to get out there and do a little more."

"When I was walking in the afternoon I, I just felt, you know, rejuvenated"

"I like walking just cause just cause it kind of just, you can totally zone out everything. Your mind is just totally empty. You don't have to think about anything, you just do it."

"when I walk I observe the trees, many different animals that I haven't seen in a long time, you know, l'll stop and look at them or, you know just take in the fresh air, you know, that can be very relaxing. That's one of the things that I admire. Yeah, just enjoying nature and being thankful."

"it's also quality time for my husband and l."

"I know for myself with my cholesterol was elevated and I started walking. And I refused to take the medication and I just walked and so there was an improvement in my cholesterol level. So when you do exercise and you see the benefits."

"And the next thing is I run at the park and it's only like a two, 30 second drive away from me"

"they have a track there now that's really nice, you know, be able to walk on and they actually have a scale that kind of measures your distance" 
Table 3 Summary of results (Product Benefits) (Continued)

Environmental

"Fun" factors

Aesthetics

"the scenery, especially in the spring and in the fall of the year is really beautiful and

sometimes it gets your attention. You really slow down and stop and take a good look

"the scenery, you in the space, it's the country that makes it fun. Just being able and, you know, hearing nature, hearing the birds and all of that stuff. It just, really does a lot for your spirit." 


\section{Question \& theme \\ Non-environmental \\ barriers/deterrents to \\ exercise \\ Time \\ Lack of motivation \\ Tending to kids/family \\ Work \\ Environmental \\ barriers/Deterrents to \\ exercise}

Safety

Lack of adequate

lighting

Dogs

\section{Non-environmental}

walking barriers/

deterrents

People

Lack of motivation

Lack of time

Lack of walking

partner

\section{Environmental}

\section{walking barriers/}

deterrents

Safety

Traffic

Inadequate lighting
"With me it's time, you know, you've got to juggle a lot, you know, throughout the day"

"I think the things for me that make it harder is right here, just getting out there and

doing it. I just will not get out there and do it like I know I should do it and like I know have done it in the past. For me it's just a mental thing really." actually getting out there and doing some exercise is kind of tough."

"I think part of the problem is, you know, what we mentioned earlier about safety too. Kids got the impression that sometimes it's not safe to be out and, you know, that wasn't a problem when I was growing up. And, you know, they, and another problem with that is, you know, as a community we have to make kids feel more safe and to be out, you know, and I think that's part of the problem with the young people."

"where the problem comes in is those children out where they can't come into the facilities."

$$
-
$$

"if anybody's with me, it slows me down"

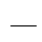

Females

"I have to be motivated and so I need somebody to motivate me to do it,

I can't do it by myself 'cause I won't, I won't."

"taking care of your family really, you know, stops you from doing all the things that you were used to doing"

"work"

"You don't see that nowadays because the elderly is in the house kind of shielding their self from the violence and all the stuff that's going on in the neighborhood."

"If there's no facility for you to exercise, you have to pay."

"the only thing I have a problem with if it's dark, there's a section that does not have any lights, so I can't do that one."

"If I'm out and the dogs are out, I can't go out there."

"just being motivated."

"not having the time"

"I got tired of walking by myself."
"I'm not comfortable walking in certain places in certain times and I feel pretty confident I can defend, but I don't want to be put in that position to have to defend."

"you walk into the parking lot cars are coming, you know, so it's just a, it's inconvenient."

"we have to get out there early because it gets dark quicker so we don't have a lot of light in the evenings. So if there was more lighting, you know, you could get out and walk" "nowadays safety has become a really big issue with walking, even in lighted areas, especially if you're walking alone." 
Table 4 Summary of results (Price) (Continued)

\begin{tabular}{|c|c|c|}
\hline Uneven terrain & $\begin{array}{l}\text { "if I step in a hole or something like that or step on something that's not, that's uneven } \\
\text { that could, that could be really bad" }\end{array}$ & $\begin{array}{l}\text { "the roads are hilly and then they have big rocks that hurt your feet and } \\
\text { whatever before you get, honestly you're tired before you reach the road, } \\
\text { you're tired." }\end{array}$ \\
\hline Lack of sidewalks & - & "in my neighborhood there aren't sidewalks" \\
\hline Dogs & - & $\begin{array}{l}\text { "when I saw the dogs I had to minimize my walking. I mean, little dogs, any } \\
\text { kind of dogs, you know, I'm just afraid of dogs." }\end{array}$ \\
\hline \multicolumn{3}{|l|}{$\begin{array}{l}\text { Who influences } \\
\text { exercising }\end{array}$} \\
\hline Neighbors/friends & $\begin{array}{l}\text { "My neighbor. Gosh, he gets out no matter what the weather's like and he runs and I'm } \\
\text { sure the area that, the circle that he takes is probably about a half a mile, three-quarters of } \\
\text { a mile and he'll run that thing and I just get tired of seeing him run it. So I had to get out } \\
\text { there and do something myself" }\end{array}$ & $\begin{array}{l}\text { "I have some ladies down from me, sometimes I will call them and let them } \\
\text { know I'm on the way and they'll be standing out there, you know, we walk } \\
\text { then, down together" }\end{array}$ \\
\hline Family & "I need to do something now because of my family's medical history." & "I got to be able to sit here and see my children's children, and their children" \\
\hline Self & - & $\begin{array}{l}\text { "it's knowing that I have to do something, I have to be active for my own } \\
\text { survival." }\end{array}$ \\
\hline Elderly & - & $\begin{array}{l}\text { "what motivates me also too is when I see people that are older than me and } \\
\text { they are so fit" }\end{array}$ \\
\hline
\end{tabular}




\section{Question \& theme \\ environmental barriers/ \\ deterrents to exercise \\ Increase lighting \\ Exercise at home \\ Time management \\ Motivation/ \\ determination \\ Help from others \\ Overcoming barriers to \\ walking}

Males

Females

Access to walking

place

Motivation/discipline

Education/discussion

Walk with others

Use alternatives

\section{Do to get others active}

Walk with others

Motivation

Role modeling

Incentives

Partner with

organization

Competition

Provide childcare
"And like you were just saying networking as you walk."

"come in through and put in more lighting in our neighborhood."

-

$-$

"I think one thing that would enhance walking and help in general just having just a universal complex that had walking trails inside and out"

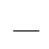

$$
\text { - }
$$

$-$

"it gonna have to be a community effort and it's still going to boil down to the individual, even doing the community effort."

"I think if, if we as adults model the fact that we need to be out walking and our children see it and our children pick up on it, and they start doing it, it becomes a habit or, or a, a routine for them."

"In the long run it saves everybody money in the community. Yep, if they could motivate us by giving discounts."

"But, you know, I was curious, but then I think that's part of the, I reckon either county council or city, whoever own the park, need to do a better job of informing people of places like that so, you know, we can realize it's there."
"I would say get started in your house, you know, in your own family, you could put it and stay in your house."

"I say time management. Cut back on watching TV"

"you just have to put your mind to it, get out there."

"I need somebody to help me be there when I'm supposed to"

"if we get the track, a walking track or something in the area"

"You say well everyday I'm gonna do my best to walk at a certain time and you have to discipline yourself like you discipline yourself to get up every morning and go to work."

"I believe education is power and I think educating people on the importance of the benefits of exercise and how we can eliminate a lot of the ... heart attacks, strokes"

"If I have somebody that I know that's going to do it with me, it's not problem."

"you can walk in place at your home"

and it does make a difference when you have someone that's right there to stay on you every day, you know, let's do it, let's not give up, you know. So I think motivating groups, I think walking groups, or whatever the case may be. Just banding together with people that have things in common to work together and make some things happen."

"think that maybe sometimes we have to throw out some incentives to get folks fired

"something like the 'biggest loser"

"Provide a babysitting service." 
Table 5 Summary of results (Promotion) (Continued)

Provide transportation

\section{Say to get others active}

Health information

Inspirational message

Who in neighborhood

\section{would encourage to get}

walking first

Community snowbal

effect

Younger people

Spouse

\section{Best way to communicate}

\section{messages}

Word of mouth

Church

ocal organizations/

groups

Sporting events

Schoo

Promotional events

Flyers "exercise brings on life, non-exercise might bring on death. [Laughter]

You know what I'm saying? We've got to get that instilled in them."

"Once somebody starts, especially if you start with your immediate family, and it, it takes like one family to really get involved in it, you know, in the in the neighborhood. And then the other children get involved and the other parents because I was telling them last night even at the meeting, we've got to go back into our communities."

"to get this back right, to get us in good health again you don't have to start not with old rascals ik

"I see in our neighborhood a tendency to target the younger people because they spend a lot of time inside now and, on the computer, on their cell phones, you know, that kind of thing. So we see a lot of our younger people becoming obese and, you know, you hear the commercial on the radio in the morning that, you know, we might outlive our children, you know, and that's sad."

"my husband."

"And that person will affect two people and then so on and so on. And you just keep going and there's that word of mouth.

"churches, faith-based communities could be an avenue"

"Well a, a lot of times with churches, you have people in the church who, who are knowledgeable. And, and a lot of times you go to church there, there are health care providers. There are lots of people with talent in there

that attend church and everybody knows and they would appreciate or,

or they would give that time and that attention to you."

"neighborhood groups"

some type of announcement at a sporting event because a lot of people like a sporting event."

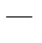


others motivated to walk, and that they would discuss health and inspiration with others. Female participants additionally cited the use of incentives, competition, and the provision of childcare as effective strategies while male participants suggested the use of role models and partnering with organizations to increase motivation for walking.

Indicating the importance of getting certain groups out to walk, both male and female participants said that younger people should be a target, and should get out walking first. Participants also agreed that a community snowball effect would get a variety of people out, "One house to the next. You just start that fire... one house to the next."

Participants were able to come up with a variety of methods to spread the word about a walking trail, with word of mouth communication via "churches, faithbased communities" as the optimal way to communicate messages. Female participants additionally liked the idea of using flyers and communicating through schools while male participants suggested partnering with local organizations and neighborhood groups.

\section{Social marketing campaign development process}

Focus group data were used to develop the intervention community social marketing campaign. Steering committee members including a community liaison, program coordinator, walking leaders, city leaders, community residents, a local pastor, city police and a communications firm worked to develop a comprehensive social marketing campaign (Tables 6 and 7). Strategic planning focused on themes around motivators for walking and overcoming barriers to walking. From these data and ongoing community input an over-arching social marketing goal was developed to motivate citizens to use the neighbhorhood walking path with others regularly and safely for increasing PA and improving health of mind, body, soul and community. Five specific objectives were developed which included (1) Increasing perceptions of the safety of walking on the path with others, (2) Creating the attitude that walking on the path will improve physical health, (3) Creating attitudes that walking on the path will improve mental health and well-being, (4) Increasing confidence in walking on the path regularly, and (5) Increasing feelings of social connectedness and perceptions of community pride by walking on the path with others.

The community steering committee also closely guided the development of a program name, logo, tag line, and the overall social marketing approach. Information from the focus groups was used to guide the development of promotional benefits of walking specifically. These themes were used by the steering committee to develop the messages on the calendars and door hangers (e.g., improve physical and mental health, social connectedness etc.). The community was concerned that the marketing materials be functional and attractive to their residents. As such, the communications firm provided the steering committee with several mock program names and logos from which the community could choose the one that best captured their vision. During this process, the steering committee developed the social marketing tag line, "A healthy you and a healthy me makes a healthy community." The steering committee and the communications firm agreed that while print materials are necessary to increase awareness of the program, a grassroots approach prioritizing personal connection with individuals would be the most effective strategy for achieving the product of walking behavior change. With these considerations in mind, a threepronged approach was developed for promotion of the social marketing campaign, and the approach was based on the themes obtained through community focus groups and tailored for delivery of the five objectives (Table 6). The primary means for delivering messages related to the five objectives was a 12-month calendar that was given to community "first time" walkers who participated in a PATH walk. Walking leaders also made a point to deliver calendars to neighbors in the target community by going door-to-door. The calendar was designed to highlight the local community through photographs of residents walking on the path. Each month the focus on one of the five objectives was highlighted in the calendar, along with goal setting and tracking of

Table 6 Process of developing social marketing promotion strategies

\begin{tabular}{|c|c|c|}
\hline Focus group themes $\rightarrow$ & Objectives $\rightarrow$ & Promotion \\
\hline $\begin{array}{l}\text { - Having access to nearby, safe places to walk } \\
\text { promotes activity }\end{array}$ & - Walking benefits physical health & $\begin{array}{l}\text { - Calendar- included photographs of community } \\
\text { walkers, objectives and goal-setting exercises }\end{array}$ \\
\hline $\begin{array}{l}\text { - Walking increases energy, benefits health, } \\
\text { and provides stress relief and opportunities } \\
\text { for meditation and spirituality }\end{array}$ & - Walking benefits mental and spiritual health & $\begin{array}{l}\text { - Door Hangers- invited new walkers, reinforced } \\
\text { objectives, and highlighted program incentives }\end{array}$ \\
\hline \multirow{3}{*}{$\begin{array}{l}\text { - Word-of-mouth among neighbors, family, } \\
\text { and friends is the most influential process } \\
\text { for affecting community behaviors }\end{array}$} & - Walking builds your confidence for being active & $\begin{array}{l}\text { - Peer Walking Leaders- facilitated grassroots } \\
\text { networking, reinforced objectives }\end{array}$ \\
\hline & - Walking builds social and community connections & \\
\hline & - Walking is safe & \\
\hline
\end{tabular}


Table 7 Social marketing components and elements

\begin{tabular}{|c|c|c|}
\hline Social marketing components & Theory elements & Practice elements \\
\hline \multirow[t]{2}{*}{ Product } & \multirow[t]{2}{*}{ Desired behavior targeted by SM. } & - Increased walking generally \\
\hline & & - Participating in the PATH walks \\
\hline \multirow[t]{4}{*}{ Price } & \multirow[t]{4}{*}{$\begin{array}{l}\text { The social, economic, and psychological and } \\
\text { physical costs involved in achieving the product. }\end{array}$} & $\begin{array}{l}\text { - Devoting time to walking; sacrificing time typically } \\
\text { spent on other activities }\end{array}$ \\
\hline & & - Driving or securing transportation to the PATH walks \\
\hline & & - Expending mental and physical energy \\
\hline & & - Perceived threats of injury and to personal safety \\
\hline \multirow[t]{3}{*}{ Place } & \multirow{3}{*}{$\begin{array}{l}\text { The setting, community context, or distribution } \\
\text { channels for the product. }\end{array}$} & - Community centers \\
\hline & & - Churches \\
\hline & & - Neighborhood walking path \\
\hline \multirow[t]{3}{*}{ Promotion } & \multirow[t]{3}{*}{$\begin{array}{l}\text { All actions designed to make the audience aware } \\
\text { of the product and its benefits. }\end{array}$} & $\begin{array}{l}\text { - Distributing campaign themes through calendars, } \\
\text { door hangers, and during walks }\end{array}$ \\
\hline & & - Grassroots strategies, Pride Strides \\
\hline & & - Local media involvement, newspaper articles \\
\hline \multirow[t]{3}{*}{ Positioning } & \multirow[t]{3}{*}{$\begin{array}{l}\text { Framing the product so that the perceived benefits } \\
\text { are maximized and the perceived costs are minimized. }\end{array}$} & $\begin{array}{l}\text { - Distributing messages that brief walks positively } \\
\text { affect health }\end{array}$ \\
\hline & & - Providing injury prevention exercises and information \\
\hline & & $\begin{array}{l}\text { - Ensuring that off-duty police are available to support } \\
\text { the program }\end{array}$ \\
\hline
\end{tabular}

walking progress. Thus, the calendar not only served as a functional tool for community residents, it was also a unique tool for increasing self-efficacy for walking.

The second set of materials included door-hangers that could be attached to neighbors front doors and that were designed to increase opportunities for personally inviting new walkers to join a PATH to HEALTH walk. Door hangers were distributed throughout the target community by PATH participating walkers and by walking leaders. The door hangers aimed to serve three purposes. First, they were used to personally invite new walkers to the group, facilitating interpersonal interaction and verbal communication about the program. Second, they complemented the calendar by reinforcing the monthly objectives and messages. Finally, they highlighted the incentives program, which would encourage walkers to do at least five walks per month to receive prizes related to the month's theme such as hand-held fans and water bottles.

The third key element of the social marketing campaign targeted the involvement of peer walking leaders. Through grassroots networking, the program engaged residents to lead peer walking groups called Pride Strides. Peer leaders would organize and lead walks for their families, friends, and professional organizations, not only by utilizing the calendars and door hangers, but also by using a field guide that outlined project details and reinforced the messages from the calendars and door hangers with talking points, inspirational poems and prayers that reflected the social marketing objectives. Thus, the peer leaders further facilitated an interpersonal channel of communication for reinforcing the social marketing messages.

Finalization of the social marketing plan centered on developing the messages, designing the print materials, and developing a protocol for implementation. In order to maximize the relevance and effectiveness of the messages, the social marketing firm encouraged the community steering committee to develop the messages that would be used throughout the calendar, door hangers, and field guide for Pride Stride leaders. Likewise, the community felt it was important that the calendar include photos of actual residents on the walking path, so the communications firm conducted a photo shoot with community partners and residents. Finally, a universal protocol for distributing social marketing materials that focused on behavior modification theory was developed to ensure the social marketing campaign was implemented with fidelity.

\section{Discussion}

This study highlights the importance of using a collaborative community process to develop a social marketing campaign to promote walking in underserved neighbourhoods and communities. Focus group data helped us to develop program deliverables that focused on a grassroots approach to inviting local neighbors out to walk. Door hangers and calendars that were culturally tailored were distributed to promote important themes for improving safety and access for walking as well as the benefits of improving health and being more socially connected. It has been noted that involving community input directly in the social marketing 
process increases the integration of a program into established community structures, which may make the program more effective and sustainable [44]. A collaborative approach to social marketing included engaging active participants in the process of program development, and working with community groups in designing, implementing, and evaluating the social marketing program prospectively [45].

One of the major strengths of this study was the use of community participation to ensure the social marketing approach was tailored and truly fit the needs of the intervention community. Residents from the PATH full intervention community and steering committee members from this community continually provided feedback on social marketing objectives, messages and modes of delivery. Consistent with our approach, Farmer and colleagues [46] have highlighted the important role of community involvement for increasing the probability of a social marketing program's success and its role in building community capacity. In addition, they suggest that involving the community at all stages or components of the social marketing process (i.e., in the " 5 P's") may result in a program that is purposefully tailored to the needs of the individual community, and therefore more likely to result in intended effects [46]. In this study both community focus groups and steering committee input were key in developing a tailored social marketing strategy to promote walking on the neighbourhood trail. Future studies should also distinguish between whether trail use may be a function of walking for leisure or for transportation [47].

Formative focus groups conducted in the PATH intervention community, as well as efforts to obtain ongoing input from the community steering committee, led to the more specific tailoring of the social marketing campaign around the community's concern for safety and the desire for a grassroots approach. A limitation of the formative process, however, was that only several of the focus groups were done with the target community neighbourhood association. Given that the PATH trial was a randomized trial several of the focus groups that were done at a near by school in a community matched on geographical demographics were conducted in advance of randomization to reduce the amount of time between program planning and implementation. However, a related strength of this study is the use of tailored messages that matched the needs of the target community. Previous research conducted during the development of the PATH trial highlighted the importance of safety issues for residents living in disadvantaged conditions [34]. Residents in the PATH full intervention community described concerns and provided specific suggestions on how to overcome barriers related to criminal activity, such as street gangs, in addition to concerns regarding stray dogs, lighting, and traffic.
One of the most important features of the PATH social marketing campaign was the grassroots approach to delivering messages to African American community members. Traditionally, campaigns designed to reach broad-based audiences have used mass media-based strategies to communicate program messages $[18,48]$. For example, Beaudoin and colleagues [49] used a mass media campaign to increase walking in a low-income, AfricanAmerican urban population in New Orleans. Messages were promoted through television advertisements, radio advertisements, taillight bus signs, large side-panel bus signs, taillight streetcar signs, and large side-panel streetcar signs. Similarly, some of the strategies used in the VERB campaign to increase PA in ethnically diverse youth and their parents included advertising on television, in print, on billboards, through a website, and through school and community-based promotions [50]. Unlike these studies, the PATH social marketing campaign used interpersonal channels of communication. Program deliverables (e.g., the 12-month calendar featuring local leaders and residents, door hangers) were designed to foster communication and were meant to be spread by local, familiar faces in the community. In addition, media efforts like local newspaper testimonials were used to highlight the community connections and safe opportunities for walking. A review of population-based interventions targeting active living in ethnic minority communities showed that in addition to non-interpersonal channels for message delivery, studies that specifically included ethnic minorities place greater emphasis on factors such as building coalitions, mobilizing social networks, and tailoring culturally specific messages [29]. In this study, interactions and conversations between neighbors, family members and friends were at the core of the grassroots approach to social marketing.

Not only were interactions between neighbors, family members, and friends important as an approach to delivering messages, the community also identified them as essential targets for message content. One of the five social marketing objectives was to increase feelings of social connectedness and perceptions of community pride by walking on the path. In addition, the social marketing tag line, "A healthy you and a healthy me makes a healthy community" highlighted the community's emphasis on the relevance of appealing to community connectedness. Consistent with Yancey and colleagues [29], this study showed the importance of incorporating community norms and activities in developing a social marketing campaign to promote walking in underserved communities. The PATH social marketing campaign was novel in that it targeted community norms by focusing specifically on family and community connectedness in both the overall approach and the tailored messages. 


\section{Conclusions}

Overall, this study suggests that developing and implementing a social marketing intervention for promoting walking in an underserved community requires ongoing community involvement. The final tailoring of the social marketing program in the target full intervention community was key to developing a program that was accepted and liked by community residents. The formative process described in this article is a model that could be used to develop community-based social marketing interventions in other underserved communities to promote walking and PA. Specifically, focus group data and community steering group involvement was critical for developing a grass roots social marketing strategy to improve safety and access for walking that is especially important for low income, ethnic minority communities.

\section{Competing interests}

The authors declare that they have no competing interests.

\section{Authors' contributions}

DKW is the Principal Investigator on the project and provided oversight for the entire project. She was the major contributor of data collection, interpretation of the data analyses and to writing of the article. SMS is a doctoral student who served as the intervention coordinator on the project. She contributed to data collection, the interpretation of the data analyses and to writing of the article. NNT is a doctoral student who served as the project director on the project. She contributed to writing the article and to the data collection and interpretation of the data analyses. SMC is a doctoral student who served as an intervention process evaluation coordinator. She contributed to the writing of the article and to the interpretation of the data analyses. SFG is a Co-Investigator on the project. She contributed to the writing of the article and to the data collection and interpretation of the data analyses. AW is a Co-Investigator on the project who contributed to the study design of the qualitative study and to the data interpretation and writing of the article. MF is a Co-Investigator on the project who contributed to the study design of the qualitative study and to the data interpretation and writing of the article. BG is are community partner who assisted with recruitment, data collection, and contributed to the writing of the article. PVB is a graduate student who assisted with conducting the focus groups, data collection, interpretation of the data analyses and to the writing of the article. All authors read and approved the final manuscript.

\section{Acknowledgements}

This article was supported by a grant (R01 DK067615) funded by the National Institutes of Diabetes, Digestive, and Kidney diseases (NIDDK) to Dawn K. Wilson, Ph.D. Send reprint requests to Dawn K. Wilson, Ph.D. Department of Psychology, Barnwell College, University of South Carolina, Columbia, SC 29208; email address: wilsondk@mailbox.sc.edu. Thanks to all our communities and to Shamika Robinson, Phil Watts, Franklin Jones, and Kaya Outen for their assistance with this project. In addition, we thank Klein Buendel Inc. for their assistance with the development of the social marketing intervention.

\section{Author details}

1Department of Psychology, University of South Carolina, Columbia, SC 29208, USA. ${ }^{2}$ Department of Public Health Sciences, College of Heath, Education, and Human Development, Clemson University, Clemson, SC 29634, USA. ${ }^{3}$ Biostatistics and Epidemiology, Arnold School of Public Health, University of South Carolina, Columbia, SC 29208, USA. ${ }^{4}$ M.H. Newton Family Life Enrichment Center, Sumter, SC, USA.

Received: 6 June 2012 Accepted: 20 February 2013

Published: 5 March 2013

\section{References}

1. Jones DA, Ainsworth BE, Croft JB, Macera CA, Lloyd EE, Yusuf HR: Moderate leisure-time physical activity: who is meeting the public health recommendations? A national cross-sectional study. Arch Fam Med 1998, 7:285-289.

2. King AC, Blair SN, Bild DE, Dishman RK: Determinants of physical activity and interventions in adults. Med Sci Sports Exerc 1992, 24:S221-236.

3. Marcus BH, King TK, Clark MM, Pinto BM, Bock BC: Theories and techniques for promoting physical activity behaviours. Sports Med 1996, 22:321-331.

4. Sallis JF, Owen N: Physical activity and behavioral medicine. Thousand Oaks, CA: Sage Publications; 1998.

5. Young DR, King AC: Exercise adherence: determinants of physical activity and applications of health behavior change theories. Med Exerc Nutr Health 1995, 4:335-348.

6. Clark DO: Identifying psychological, physiological, and environmental barriers and facilitators to excercise among older low income adults. J Clin Geropsychol 1999, 5:51-62.

7. Donato KA: Executive summary of the clinical guidelines on the identification, evaluation, and treatment of overweight and obesity in adults. Arch Intern Med 1998, 158:1855-1867.

8. Glanz K, Lankenau B, Foerster S, Temple S, Mullis R, Schmid T: Environmental and policy approaches to cardiovascular disease prevention through nutrition: opportunities for state and local action. Health Educ Beh 1995, 22:512-527.

9. Henderson KA, Ainsworth BE: Enablers and constraints to walking for older African American and American Indian women: the cross-cultural activity participants study. Res Q Excercise Sport 2000, 71:313-321.

10. King AC, Jeffery RW, Fridinger F, Dusenbury L, Provence S, Hedlund SA Spangler K: Environmental and policy approaches to cardiovascular disease prevention through physical activity: issues and opportunities. Health Educ Beh 1995, 22:499-511.

11. Lavizzo-Mourey R, Cox C, Srumpf N, Edwards WF, Stinemon M, Grisso JA: Attitudes and beliefs about excercise among elderly African Americans in an urban community. J Natl Med Assoc 2001, 93:475-480.

12. McLeroy KR, Bibeau D, Steckler A, Glanz K: An ecological perspective on health promotion programs. Health Educ Beh 1988, 15:351-377.

13. Ross R, Freeman JA, Janssen I: Exercise alone is an effective strategy for reducing obesity and related comorbidities. Exerc Sport Sci Rev 2000, 28:165-170

14. Sallis JF, Bauman A, Pratt M: Environmental and policy interventions to promote physical activity. Am J Prev Med 1998, 15:379-397.

15. Sanderson B, Littleton M, Pulley L: Environmental, policy, and cultural factors related to physical activity among rural, African American women. Womens Health 2002, 36:75-90.

16. Seefeldt VJ, Malina RM, Clark MA: Factors affecting levels of physical activity in adults. Sports Med 2002, 32:143-168.

17. Wilson DK, Trumpeter NN, St. George SM, Coulon SM, Griffin S, Van Horn ML, Lawman HG, Wandersman A, Egan B, Forthofer M, et al: An overview of the "Positive Action for Today's Health" (PATH) trial for increasing walking in low income, ethnic minority communities. Contemp Clin Trials 2010, 31:624-633.

18. Andreasen AR: Marketing social change: Changing behavior to promote health, social development, and the environment. San Francisco: Jossey-Bass; 1995

19. Lee NR, Kotler P: Social marketing: Influencing behaviors for good. 4th edition. Los Angeles, CA: Sage Publications; 2011.

20. Alcalay R, Bell RA: Promoting nutrition and physical activity through social marketing: Current practices and recommendations. Davis: Center for Advanced Studies in Nutrition and Social Marketing, University of California; 2000.

21. Kotler P, Roberto EL: Social marketing: Strategies for changing public behavior. New York, NY: Free Press; 1989.

22. Lefebvre R, Rochlin L: Social marketing. In Health Behavior and Health Education. Edited by Glanz K, Lewis F, Rimer B. San Francisco, CA: JosseyBass; 1997.

23. McGuire W: Personality and attitude change: An information-processing theory. In Psychological foundations of attitudes. Edited by Greenwald A, Brock T, Ostrom T. San Diego, CA: Academic; 1968:171-196.

24. McGuire W: Attitude change: The information processing paradigm. In Experimental Social Psychology. Edited by McClintock C. New York, NY: Holt, Rinehart \& Winston; 1972:108-141 
25. Bronfenbrenner U: Making human beings human: Bioecological perspectives on human development. Thousand Oaks, CA: Sage Publications; 2005.

26. Bronfenbrenner U: The ecology of human development: Experiments by design and nature. Cambridge, MA: Harvard University Press; 1979.

27. Bandura A: Social foundations of thought and action: A social cognitive theory. Englewood Cliffs, NJ US: Prentice-Hall, Inc; 1986.

28. Bandura A: Health promotion by social cognitive means. Health Educ Behav 2004, 31:143-164.

29. Yancey A, Kumanyika S, RD M, Ponce N, MPP W, Fielding J, Leslie J, Akbar J: Population-based interventions engaging communities of color in healthy eating and active living: a review. Population 2004, 1:3-12.

30. Anderson ES, Wojcik JR, Winett RA, Williams DM: Social-cognitive determinants of physical activity: the influence of social support, self-efficacy, outcome expectations, and self-regulation among participants in a church-based health promotion study. Health Psychol 2006, 25:510-520

31. Cohen DA, Finch BK, Bower A, Sastry N: Collective efficacy and obesity: the potential influence of social factors on health. Soc Sci Med 2006, 62:769-778.

32. Dowda M, Ainsworth BE, Addy CL, Saunders R, Riner W: Correlates of physical activity among US young adults, 18 to 30 years of age, from NHANES III. Ann Behav Med 2003, 26:15-23.

33. Fisher KJ, Li F, Michael Y, Cleveland M: Neighborhood-level influences on physical activity among older adults: a multilevel analysis. J Aging Phys Act 2004, 12:45.

34. Griffin S, Wilson DK, Wilcox S, Buck J, Ainsworth B: Physical activity influences in a disadvantaged African American community and the communities' proposed solutions. Health Promot Pract 2008, 9:180.

35. McAuley E, Jerome GJ, Elavsky S, Marquez DX, Ramsey SN: Predicting longterm maintenance of physical activity in older adults. Prev Med 2003, 37:110-118.

36. McNeill LH, Wyrwich KW, Brownson RC, Clark EM, Kreuter MW: Individual, social environmental, and physical environmental influences on physical activity among black and white adults: a structural equation analysis. Ann Behav Med 2006, 31:36-44.

37. Motl RW, Dishman RK, Saunders RP, Dowda M, Pate RR: Perceptions of physical and social environment variables and self-efficacy as correlates of self-reported physical activity among adolescent girls. J Pediatr Psychol 2007, 32:6-12.

38. Nothwehr F, Dennis L, Wu H: Measurement of behavioral objectives for weight management. Health Educ Behav 2007, 34:793-809.

39. Ogilvie D, Foster CE, Rothnie H, Cavill N, Hamilton V, Fitzsimons CF, Mutrie $\mathrm{N}$ : Interventions to promote walking: systematic review. BMJ 2007 334:1204.

40. Sampson RJ, Raudenbush SW, Earls F: Neighborhoods and violent crime: a multilevel study of collective efficacy. Science 1997, 277:918-924

41. National Center for Chronic Disease Prevention and Health Promotion: Health: A Report of the Surgeon General. Atlanta, GA: US Department of Health and Human Services, Centers for Disease Control and Prevention; 1996:017-023.

42. Strauss A, Corbin J: Basics of Qualitative Research: Techniques and Procedures for Developing Grounded Theory. 2nd edition. Thousand Oaks, CA: Sage Publications; 1998

43. Miles MB, Huberman AM: Qualitative data analysis: An expanded sourcebook. Thousand Oaks, CA: Sage Publications, Inc; 1994

44. Bryant C, Forthofer M, Landis D, McDermott R: Community-based prevention marketing: the next steps in disseminating behavior change. Am J Health Beh 2000, 24:61-68.

45. Middlestat SE, Schechter C, Peyton J, Tjugum B: Community Involvement in Health Planning: Lessons Learned from Practicing Social Marketing in a Context of Community Control, Participating and Ownership. In Social Marketing: Theoretical and Practical Perspective. Edited by Goldberg M, Fishbein M, Middlestat S. Mahway, New Jersey: Lawrence Erlbaum Associates Publishers; 1997:291-312.

46. Farmer FL, Clarke LL, Flocks JD, Bryant CA, Romund CS, Albrecht SL: Community-based social marketing: involvement in health programs. Community Dev 2002, 33:1-18.

47. Green J: 'Walk this way': public health and the social organization of walking. Soc Theory \& Health 2009, 7:20-38.
48. Randolph W, Viswanath K: Lessons learned from public health mass media campaigns: marketing health in a crowded media world. Annu Rev Public Health 2004, 25:419-437.

49. Beaudoin CE, Fernandez C, Wall JL, Farley TA: Promoting healthy eating and physical activity: short-term effects of a mass media campaign. Am J Prev Med 2007, 32:217-223.

50. Huhman M, Berkowitz JM, Wong FL, Prosper E, Gray M, Prince D, Yuen J: The VERB campaign's strategy for reaching African-American, Hispanic, Asian, and American Indian children and parents. Am J Prev Med 2008, 34:S194-S209.

\section{doi:10.1186/1479-5868-10-33}

Cite this article as: Wilson et al:: Qualitative developmental research among low income African American adults to inform a social marketing campaign for walking. International Journal of Behavioral Nutrition and Physical Activity 2013 10:33.

\section{Submit your next manuscript to BioMed Central and take full advantage of:}

- Convenient online submission

- Thorough peer review

- No space constraints or color figure charges

- Immediate publication on acceptance

- Inclusion in PubMed, CAS, Scopus and Google Scholar

- Research which is freely available for redistribution

Submit your manuscript at www.biomedcentral.com/submit
C Biomed Central 